\title{
Healthy worker effect and pregnancy: role of adverse obstetric history and social characteristics
}

\author{
BÉ NÉ DICTE STENGEL, MARIE-JOSÈPHE SAUREL-CUBIZOLLES, AND \\ MONIQUE KAMINSKI \\ From Unité de Recherches Epidémiologiques sur la Mère et l'Enfant, Institut National de la Santé et de la \\ Recherche Médicale, Villejuif, France
}

SUMMARY Data from a survey conducted in 1981 on a national sample of 5508 births in France were used to analyse the role of a history of previous adverse pregnancy outcome (spontaneous abortion, perinatal death or adverse fetal condition) in the selection mechanisms of women with regard to occupational activity, and the impact on the relation between work and preterm delivery. The study, carried out separately in each parity group, showed that occupational activity was associated with a more favourable outcome for women of parity one: the preterm delivery rate was significantly higher among women who had never worked than among those who continued working during pregnancy. However, the hypothesis of a "healthy worker effect" linked to a history of adverse obstetric outcome was not confirmed in this study. A selection effect of women from a history of spontaneous abortions was observed, but these were not linked to preterm delivery. Among multiparous women, a history of perinatal death or adverse fetal condition did not seem to modify women's behaviour towards their work. Selection mechanisms of women towards occupational activity according to sociodemographic factors were also analysed and showed that the higher percentage of younger women among those who had never worked explained the higher rate of preterm delivery in that group.

The impact of the occupational activity of pregnant women on the outcome of their pregnancy has been the object of a number of studies, as witnessed by Saurel-Cubizolles and Kaminski's review. ${ }^{1}$ Opinions have long been divided as to the existence or not of an influence of occupational activity on stillbirth, birthweight or length of gestation. Recent studies in France as in other countries, however, have displayed a certain homogeneity. If few authors have observed a relation between employment during pregnancy and birthweight or stillbirth, ${ }^{23}$ some of them have demonstrated a "favourable influence" of occupational activity on the rate of preterm deliveries, ${ }^{245}$ while emphasising that particularly difficult working conditions did represent a risk factor. ${ }^{6-8}$

However, some authors have raised the problem of biases which might exist in this type of study in which women without an occupation have been compared with women who worked during their pregnancy. These authors have discussed the relation between social and medical factors and women's occupational activity, which could lead to an erroneous interpretation of the relation observed between work and pregnancy outcome. ${ }^{9-12}$
In epidemiological studies on occupational health, the effect of selection mechanisms, which often result in a better state of health of the working population than of the general population, has been called the "healthy worker effect". ${ }^{13} 14$ As an analogy to the "healthy worker effect", Joffe, in a systematic analysis of the possible confounding factors in the study of the effect of women's work on reproductive events, has used the expression "insecure pregnancy effect". 9 One of his hypotheses is that women who have had a problem during a prior pregnancy would tend to stop working for fear of a repetition, whereas women without such prior experiences would be more likely to continue to work. In this case, pregnancies at high risk would be over-represented in the group of women without an occupation. The favourable effect of working on the pregnancy outcome would be a reflection of an autoselection of women regarding occupational activity as a function of their obstetric history.

The objective of this study was to analyse this phenomenon using data from a national survey carried out by INSERM (the French Institut National de la Santé et de la Recherche Médicale) in 1981 on a representative sample of 5508 births. Two questions 
were considered:

1 Is the behaviour of pregnant women relative to their occupational activity different according to whether or not they have had a history of adverse obstetric outcome? In order better to identify a possible selection mechanism among those women without an occupation during their current pregnancy, we distinguished those who had never worked from those who had worked but stopped at any time before the index pregnancy.

2 Might such a selection mechanism explain the favourable relation observed between occupational activity and preterm birth? To answer this question, the relation between working and preterm birth was studied in a multivariate analysis, taking into account, in addition to the obstetric history of the women, the social and demographic characteristics susceptible of intervening as "confounders".

\section{Population and methods}

This study was carried out using data gathered in a national survey performed by INSERM in 1981 on a representative sample of births in France. The sample was obtained by random selection of births at public and private maternity units throughout France which were also randomly selected. The sample thus obtained included 5508 women. ${ }^{15}$

The data were collected:

(a) by interviewing the mothers, while still in hospital, within five days following the birth. The questions concerned their obstetric history, social and demographic characteristics, and occupational activity before and/or during pregnancy.

(b) from the medical records for all data concerning the delivery and the child's condition at birth.

The principal aim of the survey had been to evaluate the perinatal health and health care during pregnancy, delivery, and the neonatal period. ${ }^{15}$

In order to study the factors likely to influence women with regard to their work, three groups of women were distinguished according to whether or not they were working during the index pregnancy and/or before it.

The first group, designated "employed during pregnancy" in the tables, worked before and during this pregnancy.

The second group, "employed before pregnancy" in the tables, had previously exercised an occupation but had ceased before the index pregnancy.

In the third group, designated "never employed", the women had never had an occupation.

The definitions of these groups led to the exclusion of 414 women; 356 were unemployed/seeking employment (167 women), or students ( 58 women), or the data concerning work were missing (131 women); 58 women said they had been working during this pregnancy but had never worked prior to it.

The analysis was carried out separately for each parity group in order to take into account the relations between adverse obstetric history and number of previous deliveries, on the one hand, and the number of children and having a job, on the other.

Among the factors likely to influence the behaviour of women relative to their occupational activity, we have studied those known to be associated with a perinatal risk. ${ }^{16-19}$

(1) The adverse obstetric outcomes analysed were: (a) a history of at least one spontaneous abortion; and (b) a history of at least one perinatal death or adverse fetal condition. Three subgroups were constituted:

Group 1: women having had at least one perinatal death (designated "perinatal death" in tables)

Group 2: women with infants all surviving the perinatal period but at least one being malformed, preterm or of birthweight less than $2500 \mathrm{~g}$ (designated "adverse fetal condition")

Group 3: women with infants all surviving the perinatal period with none of the adverse conditions described for group 2 (designated "normal infants" in the tables).

If the women did not mention any adverse history, their previous pregnancies were considered to have been normal. Only previous multiple births were excluded (33 cases).

(2) The following sociodemographic factors were studied: the age of the mother, her nationality (French or foreign), and her level of education, divided into four classes:

Class 1: lower educational level, up to 8 years of primary education without diploma

Class 2: intermediate educational level, 9 to 11 years of schooling

Class 3: upper educational level, 12 or more years of schooling

Class 0: all those women for whom educational data were lacking.

Finally, the occupation of the women who worked prior to the index pregnancy, and the reasons why they stopped, were analysed.

The indicators selected to describe the outcome of the index pregnancy were the rate of preterm deliveries as defined by a gestational age less than 37 weeks since the date of the last menstrual period, and the percentage of babies having a birth weight of less than $2500 \mathrm{~g}$. The date of the last menstrual period was unknown for 353 women, that is $7 \%$ of the sample, and the baby's birthweight was unknown for 24 women. 
The analysis was conducted in parallel for the first three parity groups: women of parity 0 or nulliparae (2018 women), women of parity 1 (1753 women), and women of parity 2 (834 women). Women having had three or more children before this pregnancy ( 468 women) were excluded from this study. The numbers for each of the parity groups beyond parity 3 were too small to permit analysis, and grouping them together presented methodological problems in the analysis of obstetric history. The occupational activity and index pregnancy outcome for these women were, however, described.

For each of the three parity groups, the obstetric history and social factors were analysed in relation to occupational activity, on the one hand, and the outcome of the index pregnancy, on the other. All of these factors have been taken into account in a multivariate analysis using a logistic regression in order to evaluate their influence on the relation observed between working and preterm delivery, and to calculate adjusted odds ratios of preterm delivery as a function of working. ${ }^{20}$

The statistical method used was Pearson's $\chi^{2}$ and was carried out at INSERM's Centre de Calcul using the software Pastis. The logistic regression was done using BMDP software.

\section{Results}

EMPLOYMENT OF WOMEN DURING PREGNANCY ACCORDING TO PARITY AND HISTORY OF ADVERSE OBSTETRIC OUTCOME

The rate of occupational activity of all women in the sample was $57 \%$ but it varied considerably according to parity (table 1). It was very high among nulliparae and decreased as the number of children increased.

The percentage of women who had never worked was highest for those women having had three or more previous children. Among the other parity groups, about $40 \%$ of the women not working during the index pregnancy had worked previously.
Table 1 Women's occupational activity by parity

\begin{tabular}{|c|c|c|c|c|}
\hline \multirow[b]{2}{*}{ Parity } & \multirow[b]{2}{*}{ No. } & \multicolumn{3}{|c|}{ Occupational activity } \\
\hline & & $\begin{array}{l}\text { Employed } \\
\text { during } \\
\text { pregnancy } \\
\%\end{array}$ & $\begin{array}{l}\text { Employed } \\
\text { before } \\
\text { pregnancy } \\
\%\end{array}$ & $\begin{array}{l}\text { Never } \\
\text { employed } \\
\%\end{array}$ \\
\hline 0 & 2018 & 73 & 12 & 15 \\
\hline 1 & 1753 & 57 & 19 & 23 \\
\hline 2 & 834 & 38 & 24 & 38 \\
\hline 3 or more & 468 & 19 & 18 & 63 \\
\hline Total & 5073 & 57 & 17 & 26 \\
\hline
\end{tabular}

The frequency of adverse history increased with parity; $8 \%, 12 \%$, and $14 \%$ respectively of the women of parity 0,1 , and 2 had had at least one spontaneous abortion; $2 \%$ of women of parity 1 and $7 \%$ of women of parity $2 \mathrm{had}$ had at least one perinatal death, while $8 \%$ and $12 \%$ respectively had had at least one child with a congenital malformation, a birthweight less than $2500 \mathrm{~g}$, or born preterm.

Women of parity 0 and 2 who had had spontaneous abortions were more likely to have left their job than women without such a history, while among women of parity 1 no such relation was observed (table 2).

The behaviour of the multiparae (ie, women of parity 1 or more) towards employment was not statistically different according to whether or not they had had a history of adverse obstetric outcome (table 3). In particular, those having a history of perinatako death did not work more frequently than the others,? and those with a history of adverse fetal condition did not more often leave their work.

In addition, no behavioural differences concerning work were observed for women having had a history of more than one adverse obstetric outcome (spontaneous abortion and/or perinatal death or adverse fetal condition) as compared to those who had had none or only one such adverse outcome.

Table 2 Women's occupational activity by history of spontaneous abortion and parity

\begin{tabular}{|c|c|c|c|c|c|c|}
\hline \multirow[b]{2}{*}{ Parity } & \multirow[b]{2}{*}{$\begin{array}{l}\text { Previous } \\
\text { spontaneous } \\
\text { abortion }\end{array}$} & \multirow[b]{2}{*}{ No. } & \multicolumn{4}{|c|}{ Occupational activity } \\
\hline & & & $\begin{array}{l}\text { Employed } \\
\text { during } \\
\text { pregnancy } \\
\%\end{array}$ & $\begin{array}{l}\text { Employed } \\
\text { before } \\
\text { pregnancy } \\
\%\end{array}$ & $\begin{array}{l}\text { Never } \\
\text { employed } \\
\% / \%\end{array}$ & $p$ \\
\hline 0 & $\begin{array}{l}\text { Yes } \\
\text { No }\end{array}$ & $\begin{array}{r}154 \\
1852\end{array}$ & $\begin{array}{l}68 \\
74\end{array}$ & $\begin{array}{l}21 \\
11\end{array}$ & $\begin{array}{l}12 \\
15\end{array}$ & ** \\
\hline 1 & $\begin{array}{l}\text { Yes } \\
\text { No }\end{array}$ & $\begin{array}{r}203 \\
1546\end{array}$ & $\begin{array}{l}61 \\
57\end{array}$ & $\begin{array}{l}21 \\
19\end{array}$ & $\begin{array}{l}18 \\
24\end{array}$ & ns \\
\hline 2 & $\begin{array}{l}\text { Yes } \\
\text { No }\end{array}$ & $\begin{array}{l}114 \\
720\end{array}$ & $\begin{array}{l}34 \\
38\end{array}$ & $\begin{array}{l}37 \\
22\end{array}$ & $\begin{array}{l}29 \\
40\end{array}$ & $* *$ \\
\hline
\end{tabular}

ns $p>0.05$

$* * p<0.01$ 
EMPLOYMENT OF WOMEN DURING PREGNANCY ACCORDING TO SOCIAL AND DEMOGRAPHIC CHARACTERISTICS AND TO PARITY

Having an occupation was significantly linked to the age of the women and to their level of education (tables 4 and 5). In each of the parity groups, the proportion who worked was lower and the percentage of women never having worked was greater as the women were younger and their level of education lower.

Similarly, the proportion of working women among the French was twice as high as among foreign women, for each parity; these latter were more likely never to have been employed.

Furthermore, whether a woman continued to work or not was highly linked to the nature of her previous occupation. Among the women of parity 2, $75 \%$ of professionals worked during their pregnancy, while only $60 \%$ of clerical workers and $53 \%$ of manual workers did so.

Lastly, the analysis of the reasons that led women to abandon their occupation showed that half of the multiparae stopped due to the birth of a child while those of parity 0 most often mentioned unemployment; however, $15 \%$ of the latter claimed to have stopped working in anticipation of this pregnancy. Among all the parity groups, only $6 \%$ of the women claimed to have stopped working for health reasons.

EMPLOYMENT AND PREGNANCY OUTCOME ACCORDING TO PARITY

The rate of preterm delivery for the whole sample

Table 3 Women's occupational activity by history of perinatal death or adverse fetal condition and parity

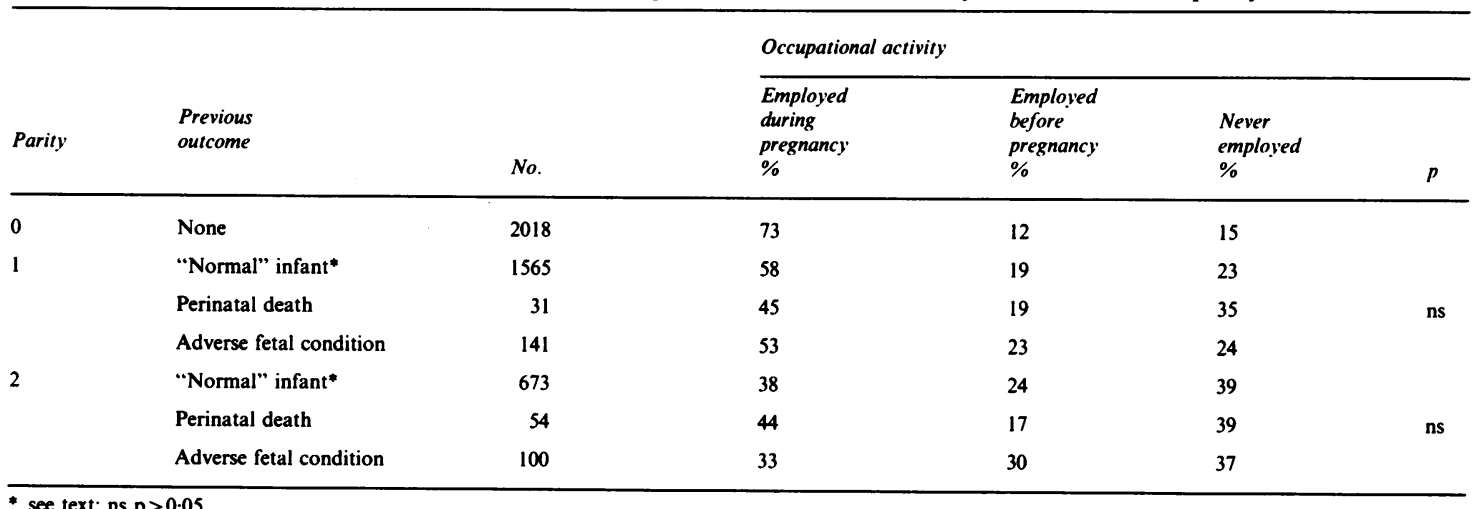

Table 4 Women's occupational activity by level of education and parity

\begin{tabular}{|c|c|c|c|c|c|c|}
\hline \multirow[b]{2}{*}{ Parity } & \multirow[b]{2}{*}{$\begin{array}{l}\text { Level of } \\
\text { education }\end{array}$} & \multirow[b]{2}{*}{ No. } & \multicolumn{4}{|c|}{ Occupational activity } \\
\hline & & & $\begin{array}{l}\text { Employed } \\
\text { during } \\
\text { pregnancy } \\
\%\end{array}$ & $\begin{array}{l}\text { Employed } \\
\text { before } \\
\text { pregnancy } \\
\%\end{array}$ & $\begin{array}{l}\text { Never } \\
\text { employed } \\
\%\end{array}$ & $p$ \\
\hline 0 & $\begin{array}{l}\text { Unknown } \\
\text { Lower } \\
\text { Intermediate } \\
\text { Upper }\end{array}$ & $\begin{array}{r}93 \\
512 \\
877 \\
536\end{array}$ & $\begin{array}{l}53 \\
59 \\
77 \\
84\end{array}$ & $\begin{array}{r}10 \\
15 \\
12 \\
9\end{array}$ & $\begin{array}{r}38 \\
25 \\
12 \\
7\end{array}$ & $* * *$ \\
\hline 1 & $\begin{array}{l}\text { Unknown } \\
\text { Lower } \\
\text { Intermediate } \\
\text { Upper }\end{array}$ & $\begin{array}{r}76 \\
513 \\
739 \\
425\end{array}$ & $\begin{array}{l}34 \\
43 \\
62 \\
71\end{array}$ & $\begin{array}{l}12 \\
23 \\
20 \\
16\end{array}$ & $\begin{array}{l}54 \\
34 \\
18 \\
14\end{array}$ & $* * *$ \\
\hline 2 & $\begin{array}{l}\text { Unknown } \\
\text { Lower } \\
\text { Intermediate } \\
\text { Upper }\end{array}$ & $\begin{array}{r}67 \\
335 \\
271 \\
161\end{array}$ & $\begin{array}{l}19 \\
27 \\
41 \\
63\end{array}$ & $\begin{array}{l}10 \\
24 \\
29 \\
20\end{array}$ & $\begin{array}{l}70 \\
49 \\
30 \\
17\end{array}$ & *** \\
\hline
\end{tabular}


(including women of parity 3 or more) was $5 \%$ and varied significantly according to occupational activity but not according to parity (table 6). However, the relation between work and preterm delivery varied according to the number of children.

Among women of parity 0 , this relation was globally significant, although with no evidence of a significant relative risk in either of the two groups of women not working during the index pregnancy as compared to the reference group of women who were working.

Among women of parity 1 , the relation between occupational activity and preterm delivery was statistically significant, and the risk was greater among women who had never worked as compared to those of the reference group.

In the higher parity groups, no relation between work and preterm delivery was observed.

In addition, no relation was found between work and the birth of a baby weighing less than $2500 \mathrm{~g}$ for the whole of the sample or for any one of the parity groups.

RATE OF PRETERM DELIVERY ACCORDING TO OBSTETRIC HISTORY, SOCIAL AND DEMOGRAPHIC CHARACTERISTICS, AND PAR ITY

The rate of preterm delivery among women who had had at least one spontaneous abortion was not significantly greater than for women with no such history (table 7). On the other hand, multiparae who had had a history of stillbirth or other adverse fetal outcome had a preterm delivery rate two to three times higher than that of women with no adverse obstetric history.

The youth of the mother, a low educational level, and a foreign nationality were significantly associated with a high level of preterm delivery among

Table 5 Women's occupational activity by age at delivery and parity

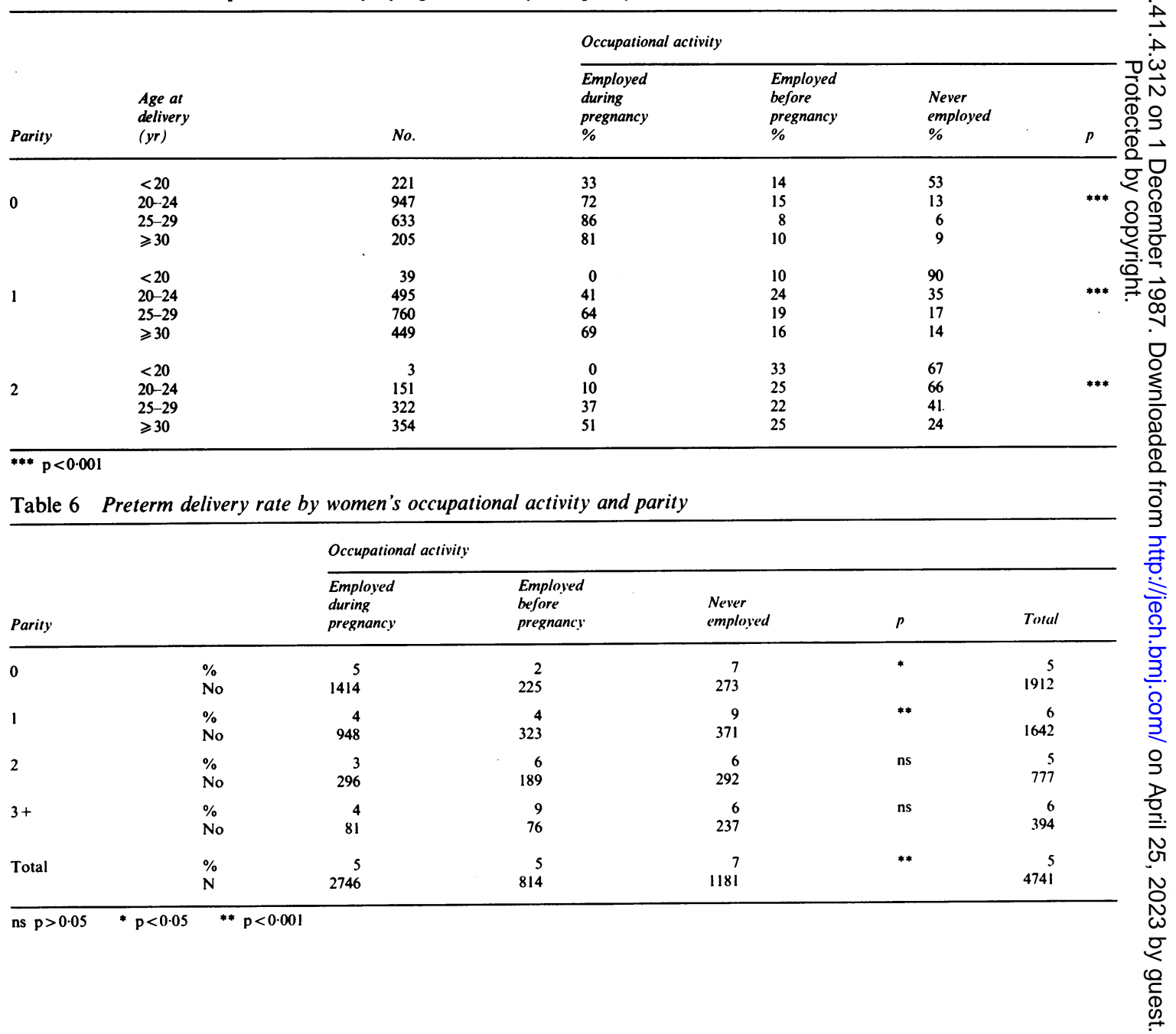


multiparae. Among women of parity 0, only a delivery among women who had never worked tendency was observed.

INFLUENCE OF OBSTETRIC HISTORY AND SOCIAL FACTORS ON RELATION BETWEEN WORK AND PRETERM DELIVERY: RESULTS OF MULTIVARIATE ANALYSIS

Among women of parity 1 , after adjustment for all the risk factors, the relation observed between occupational activity and preterm delivery was no longer significant, and the higher risk of preterm disappeared (table 8). The stepwise analysis also showed that taking age into account could by itself explain the relation observed between work and preterm delivery in this parity group.

However, for those of parity 0 , taking these factors into account did not modify the overall association between work and preterm delivery, but the rate of preterm delivery became significantly lower among women who had ceased working as compared to those who continued during this pregnancy.

Table 7 Preterm delivery rate by women's obstetric history and social characteristics, and by parity

\begin{tabular}{|c|c|c|c|c|c|c|c|c|}
\hline \multirow{3}{*}{$\begin{array}{l}\text { Women's } \\
\text { characteristics }\end{array}$} & \multicolumn{8}{|l|}{ Parity } \\
\hline & \multicolumn{2}{|l|}{0} & \multicolumn{3}{|l|}{1} & \multicolumn{3}{|l|}{2} \\
\hline & No. & $\%$ & No. & $\%$ & & No. & $\%$ & \\
\hline \multicolumn{9}{|l|}{ Previous spontaneous abortion } \\
\hline No & 1757 & 5 & 1443 & 6 & & 669 & 5 & \\
\hline Yes & 143 & $8 \mathrm{~ns}$ & 195 & 6 & ns & 108 & 4 & ns \\
\hline \multicolumn{9}{|l|}{ Previous outcome } \\
\hline "Normal" infant ${ }^{\mathrm{a}}$ & & & 1468 & 5 & & 630 & 4 & \\
\hline Perinatal death & & & 28 & 14 & * & 50 & & ** \\
\hline Adverse fetal condition & & & 132 & 10 & & 90 & 11 & \\
\hline \multicolumn{9}{|l|}{ Age at delivery (yr) } \\
\hline$<20$ & 191 & 8 & 34 & 26 & & 3 & 0 & \\
\hline $20-24$ & 901 & $6 \mathrm{~ns}^{\mathrm{b}}$ & 452 & 8 & $* * *$ & 132 & 9 & $\mathrm{~ns}^{\mathrm{c}}$ \\
\hline $25-29$ & 609 & 4 & 713 & 4 & & 303 & 5 & \\
\hline$\geqslant 30$ & 200 & 4 & 434 & 5 & & 335 & 3 & \\
\hline \multicolumn{9}{|l|}{ Level of education } \\
\hline Unknown & 88 & 8 & 69 & 12 & & 54 & 6 & \\
\hline Lower & 463 & $6 \mathrm{~ns}$ & 470 & 8 & * & 307 & 6 & ns \\
\hline Intermediate & 843 & 5 & 696 & 5 & & 259 & 4 & \\
\hline Upper & 518 & 3 & 407 & 4 & & 157 & 4 & \\
\hline \multicolumn{9}{|l|}{ Nationality } \\
\hline French & 1790 & 5 & 1511 & 5 & & 686 & 4 & \\
\hline Other & 120 & $6 \mathrm{~ns}$ & 129 & 10 & * & 89 & 11 & $* *$ \\
\hline
\end{tabular}

Table 8 Relative risk of preterm delivery of women never employed and women who have stopped working compared with women employed during pregnancy, by parity

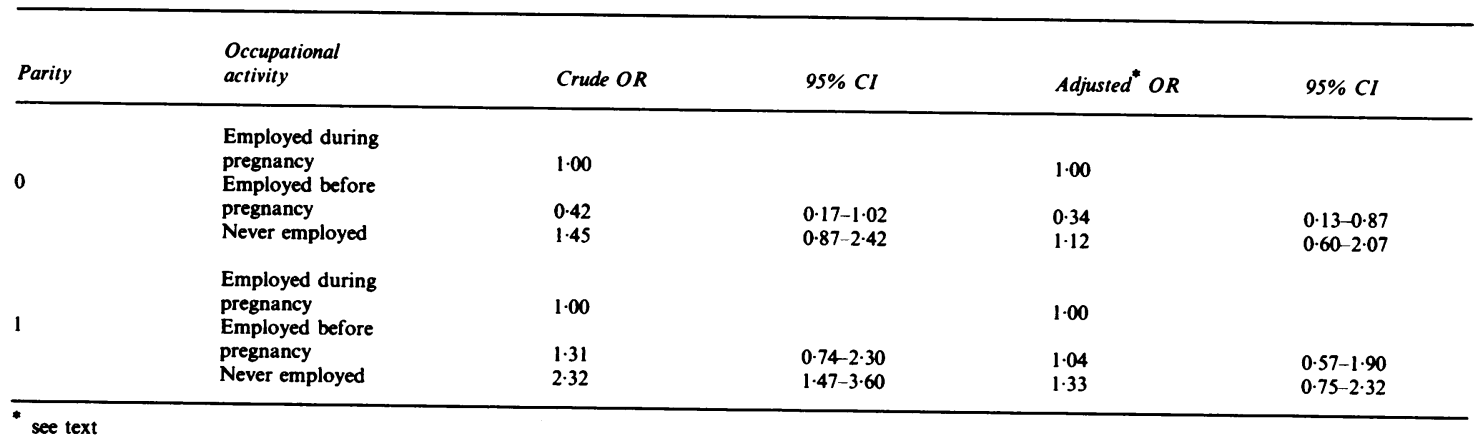




\section{Discussion}

OCCUPATIONAL ACTIVITY AND NUMBER OF CHILDREN

Over the past 30 years, the number of women who are employed has increased considerably in France as well as elsewhere. ${ }^{21}$ In particular, the rate of occupational activity for women aged 25 to 40 has shown a steep rise, reflecting the current trend for women to continue working after the birth of a first or second child instead of awaiting the completion of the family to start or resume an occupation, as had formerly been the custom. ${ }^{22}{ }^{23}$ However, the influence of a birth on a woman's occupational activity remains decisive and led us to analyse the behaviour of women relative to work, separately for each parity.

OCCUPATIONAL ACTIVITY AND OUTCOME OF PREGNANCY

In the most recent surveys, the pregnancy outcome for working women often appeared more favourable than for those who were not employed, whether in terms of preterm delivery 245 or birth of children weighing less than $2500 \mathrm{~g} .{ }^{23}$ Some authors, however, found no relation between work and pregnancy outcome. ${ }^{724}$

This study did not show any relation between occupational activity and low birthweight. On the other hand, a relation did exist between occupational activity and preterm delivery, but this relation varied according to parity. Among women of parity 1, only those who had never worked had a rate of preterm delivery significantly higher than that for those who were working. Among women of parity 0 , the situation was more complex: while the rate of preterm delivery was linked overall to occupational activity, it was not significantly different in either of the non-working groups compared to the reference group of women who continued to work during this pregnancy.

The definition of preterm delivery in this study was based on the length of gestation calculated from the date of the last menstrual period. This information was missing for $6 \%$ of the women. However, in the survey the length of gestation could also be measured from the expected date of delivery estimated by the clinician during pregnancy. ${ }^{15}$ Among the multiparae, even if a difference between the two estimations of gestation length did exist for some women, it did not modify the relation observed between working and preterm delivery. Among women of parity 0 , the differences were such that a relation between working and preterm delivery estimated from the expected date of delivery was no longer observed. Although there was no argument which could affirm that estimation by the second method was more reliable than dating from the last menstrual period, the instability of the relation according to the indicator of gestation length used made it difficult to draw any conclusions concerning women of parity 0 .

SELECTION MECHANISMS OF WOMEN RELATIVE TO OCCUPATION ACTIVITY: ROLE OF SOCIODEMOGRAPHIC FACTORS

Sociodemographic studies on women's occupational activity have shown that, apart from the size of the family, other factors had a determinant influence over whether or not the women continued their jobs. These are their educational level, the nature of their occupation, and the socioprofessional category of their spouse. ${ }^{22} 23$ These factors act as a selection process which results in very different sociodemographic profiles between women according to whether or not they have an occupation. In our study, as in others, ${ }^{2324}$ in all parity groups the social and demographic profile of the women who had never worked was the least favourable: least educated, youngest, and foreign. The characteristics of the women who had ceased working were in between these and those of the women who continued working during the index pregnancy. These characteristics are associated with a higher risk of preterm delivery, ${ }^{616} 25-27$ as confirmed by this study at least for multiparae, while among women of parity 0 , this tendency was not statistically significant.

In epidemiological studies, the social category of women is often defined by the occupational category of their spouse. ${ }^{2} 318$ The indicator used in this study was the level of education of the mother, this information permitting the characterisation of all the women by data pertaining to them alone. In addition, the women for whom the level of education was unknown, very different from the other women in terms of occupational activity and preterm delivery rates, were included in this study. However, neither their educational level nor their nationality explained the higher rate of preterm delivery among the women never having worked although educational level had partly explained it in another study. ${ }^{5}$

On the other hand, the age of the mother appeared here as a confounding factor in the relation between work and preterm delivery, in particular among the women of parity 1 . Indeed, among this group, a very high rate of preterm delivery was observed in women under the age of 20 , as has previously been noted, $1826-28$ but also in women aged 20-24, who are numerous in this parity group.

"HEALTHY WORKER EFFECT", AND PREGNANCY: ROLE OF ADVERSE OBSTETRIC HISTORY

The hypothesis of an "insecure pregnancy effect" (by analogy with the "healthy worker effect") linked to an adverse obstetric history raised by $\mathrm{Joffe}^{9}$ as a possible 
explanation for the apparently favourable effect of working on pregnancy outcome, was not verified in this study. In fact, in this national sample of women, the frequency of a history of adverse obstetric outcome was low (less than $15 \%$ ) in all the parity groups. In addition, if the women who had had a history of spontaneous abortions were more likely to have left their jobs as compared to women without such histories, no significant relation was observed between such histories and preterm delivery. Conversely, the existence of a history of adverse obstetric outcome, such as perinatal death or adverse fetal condition, highly linked to preterm delivery among the multiparae did not seem to modify the behaviour of women towards employment.

However, certain facts should be noted:

(a) The validity of the information concerning obstetric history collected retrospectively has been widely discussed in the literature. ${ }^{10} 1129-31$ In this study, the fact that the women who had not declared adverse outcomes were considered as having had normal pregnancies might have led to an overall underestimation of these histories and to a lack of power in the analysis of its relation to work.

(b) No relation was observed between the existence of a history of perinatal death or adverse fetal condition and occupational activity. However, one may not assume absence of influence of the birth of an unhealthy baby on women's behaviour towards work. Indeed, in this type of study (cross-sectional), the succession in which the occupational and reproductive events have happened in the life of the woman is unknown, and only a longitudinal study would permit the verification of this hypothesis.

(c) Several authors have suggested the possibility of observing a higher percentage of previous spontaneous abortions among women who worked in comparison with those who did not, as a result of the hypothesis that women who had spontaneous abortions were more likely to continue to work than those for whom the pregnancy ended with the birth of a child. ${ }^{9} 1032$ Our study, on the contrary, showed a higher percentage of history of spontaneous abortions among women who had stopped working relative to those who worked during their pregnancy and to those who had never worked. Even if for the same reason as previously cited (cross-sectional study) a causal relation may not be concluded between a history of spontaneous abortion and the fact of stopping work, one may wonder if there is not a selection mechanism, as observed by Hemminki et al. ${ }^{12}$

(d) In this study, a history of spontaneous abortion was not associated with a higher risk of preterm delivery, even after considering the total number of previous abortions. However, several authors consider a history of spontaneous abortion as a risk factor for preterm delivery 161819 although some specify that it was so only in the case of repeated spontaneous abortions or those occurring in the second trimester. ${ }^{33} 34$ Furthermore, a history of spontaneous abortion, as for perinatal death or adverse fetal outcome, may be associated with other types of adverse pregnancy outcome. ${ }^{17} 193536$

Altogether, despite not having demonstrated a "healthy worker effect" linked to a history of adverse obstetric outcome in this study, the existence of such a phenomenon may not be excluded in other studies on the effect of women's work on reproductive events.

In addition, the "healthy worker effect" generally refers to a selection mechanism according to the state of health. ${ }^{1314}$ To our knowledge, only Murphy et al, ${ }^{2}$ have taken the women's state of health into account in the analysis of the relation between work and pregnancy outcome. They have shown that, after the exclusion of sick women or those having histories of spontaneous abortions, the apparently favourable effect of work on perinatal death and birth of lowweight infants disappeared but not that on preterm delivery. In our study, data concerning the women's state of health were not available but only $6 \%$ of the women had said that they had left their jobs for health reasons.

These results emphasise the major selective effect towards occupational activity of parity and women's social characteristics such that it appeared impossible to isolate the effect of work, by itself, on pregnancy outcome. This was somewhat confirmed by the observation of results differing according to parity. The fact that the social characteristics of working women have evolved over time and vary according to country may explain certain contradictory results in studies on pregnancy and work. It also suggests that the confounding factors to consider in these studies may vary according to the local situation regarding both employment and health. Likewise, similar selection mechanisms may be suspected in studies comparing, among working women, pregnancy outcome according to occupation or working conditions.

In addition, it would be interesting to confirm the role of spontaneous abortion in the selection towards occupational activity, as observed in this study, by a longitudinal analysis of the relation between reproductive events and a change in women's occupational activity.

We would like to thank Jo-Anne Marie for her help in translation, and Monique Corre and Virginie Viaggio who typed the manuscript.

The study was supported partly by a grant from the French Department of Health. 
Reprint requests to Bénédicte Stengel, INSERM Unité 149, 16, avenue Paul Vaillant Couturier, 94807 Villejuif Cedex, Fance.

\section{References}

${ }^{1}$ Saurel-Cubizolles MJ, Kaminski M. Work in pregnancy: its evolving relationship with perinatal outcome (a review). Soc Sci Med 1986; 22: 431-42.

${ }^{2}$ Murphy JF, Dauncey M, Newcombe R, Garcia J, Elbourne D. Employment in pregnancy: prevalence, maternal characteristics, perinatal outcome. Lancet 1984; i: $1163-6$.

${ }^{3}$ Gofin J. The effect on birth weight of employment during pregnancy. J Biosoc Sci 1979; 11: 259-67.

${ }^{4}$ Akkerman S, Towe J, Voigt M. Zum Einflub sozialer Faktoren auf die Beziehungen zwischen mütterlicher Berufstätigkeit und Frühgeborenenquote. Zdl Gynäk 1976; 98: 193-9.

${ }^{5}$ Saurel-Cubizolles MJ, Kaminski M, Rumeau-Rouquette C. Activité professionnelle des femmes enceintes surveillance prénatale et issue de la grossesse. J Gynecol Obstet Biol Reprod 1982; 11: 959-67.

${ }^{6}$ Mamelle N, Laumon B, Lazar P. Prematurity and occupational activity during pregnancy. Am J Epidemiol 1984; 119: 309-22.

${ }^{7}$ Chamberlain G. Pregnant women at work. London: Macmillan, 1984.

${ }^{8}$ Saurel-Cubizolles MJ, Kaminski M, Llado-Arkhipoff J, du Mazaubrun C, Estryn-Behar M, Berthier C, Mouchet M, Kelfa C. Prenancy and its outcome among hospital personnel, according to occupation and working conditions. J Epidemiol Coummunity Health 1985; 39: 129-34.

${ }^{9}$ Joffe M. Biases in research on reproduction and women's work. Int J Epidemiol 1985; 14: 118-23.

${ }^{10}$ Selevan SG. Design considerations in pregnancy outcome studies of occupational populations. Scand J Work Environ Health 1981; 7 (suppl 4): 76-82.

${ }^{11}$ Hemminki K, Axelson O, Niemi ML, Ahlborg G. Assessment of methods and results of reproductive occupational epidemiology: spontaneous abortions and malformations in the offspring of working women. Am J Ind Med 1983; 4: 293-307.

${ }^{12}$ Hemminki K, Miemi ML, Kyyronen P, Kilpikari K, Vainio $H$. Spontaneous abortions and reproductive selection mechanisms in the rubber and leather industry in Finland. Br J Ind Med 1983; 40: 81-6.

13 Vinni K, Hakama M. Healthy worker effect in the total Finnish population. Br J Ind Med 1980; 37: 180-4.

14 Waldron I, Herold J, Dunn D, Staum R. Reciprocal effects of health and labor force participation among women: evidence from two longitudinal studies. $J$ Occup Med 1982; 24: 126-32.

15 Rumeau-Rouquette C, Du Mazaubrun C, Breart G. Protocole in Rumeau-Rouquette C, Du Mazaubrun C, Rabarison Y, eds. Naitre en France, 10 ans d'évolution. Paris: INSERM-Doin, 1984; 3-17.

16 Fedrick J, Anderson A. Factors associated with spontaneous preterm birth. Br J Obstet Gynaecol 1976; 83: $342-50$.
${ }^{17}$ Fedrick J, Aldestein P. Factors associated with low birth weight of infants delivered at term. Br J Obstet Gynaecol 1978; 85: 1-7.

${ }^{18}$ Berkowitz G. An epidemiologic study of preterm delivery. Am J Epidemiol 1981; 113: 81-92.

${ }^{19}$ Funderburk S, Guthrie D, Meldrum D. Suboptimal pregnancy outcome among women with prior abortions and premature births. Am J Obstet Gynecol 1976; 1: $55-60$.

${ }^{20}$ Breslow N, Day N. Statistical methods in cancer research: the analysis of case-control studies. Lyon: IARC; 1980.

${ }^{21}$ Eurostat. Economic and social position of women in the community. Luxembourg: Office des Publications Officielles des Communautés Européennes, 1981.

22 Martin J. Returning to work after childbearing: evidence from the Women and Employment Survey. Pop Trends 1986; 43: 23-30.

23 Villeneuve-Gokalp C. Incidences des charges familiales sur l'organisation du travail professionnel des femmes. Population 1985; 2: 267-98.

${ }^{24}$ Marbury MC, Linn S, Monson RR, Wegman DH, Schoenbaum SC, Stubblefield PG, Ryan KJ. Work and pregnancy. J Occup Med 1984; 26: 415-21.

${ }^{25}$ Stengel B, Saurel-Cubizolles MJ, Kaminski M. Pregnant immigrant women: occupational activity, antenatal care and outcome. Int J Epidemiol 1986; 15: 533-9.

${ }^{26}$ Blondel B, Kaminski M, Saurel-Cubizolles MJ, Breart G. Pregnancy outcome and social condition of women under 20: Evolution in France from 1972 to 1981. Int Epidemiol (in press).

${ }^{27}$ Bakketeig L, Hoffman H. Epidemiology of preterm birth results from a longitudinal study of births in Norway. In Preterm labor. Elder M, Hendricks C, Eds. London Butterworth, 1981, 17-46.

${ }^{28}$ Blondel B, Kaminski M. A propos de "la grossesse chez les< adolescentes". J Gynecol Obstet Biol Reprod 1986; 15 239.

${ }^{29}$ Axelsson G, Rylander R. Validation of questionnaire reported miscarriage, malformation and birth weight. In $J$ Epidemiol 1984; 13: 94-8.

30 Tilley B, Barnes A, Bergstralh E, Labarthed, Noller K, Colton T, Adam E. A comparison of pregnancy history recall and medical records. Am J Epidemiol 1985; 121: 269-81.

${ }^{31}$ Zeuthen Heidam L, Olsen J. Self-reported data on spontaneous abortions compared with data obtained by computer linkage with the hospital registry. Scand J Soc Med 1985; 13: 159-63.

${ }^{32}$ Axelsson G. Selection bias in studies of spontaneous abortion among occupational groups. J Occup Med 1984; 26: $525-8$.

${ }^{33}$ Carr-Hill $\mathbf{R}$, Hall $\mathbf{M}$. The repetition of spontaneous preterm labour. Br J Obstet Gynaecol 1985; 92: 921-8.

${ }^{34}$ Keirse M, Rush R, Anderson A, Turnbull A. Risk of preterm delivery in patients with previous preterm delivery and/or abortion. Br J Obstet Gynaecol 1978; 85: $81-5$.

${ }^{35}$ Miller H, Jeckel J. Associations between unfavourable outcomes in successive pregnancies. Am J Obstet Gynecol 1985; 1: $20-4$

${ }^{36}$ Strobino B, Fox H, Kline J, Stein Z, Susser M, Waburton D. Characteristics of women with recurrent spontaneous abortions and women with favourable reproductive histories. Am J Publ Health 1986; 76: 986-91.

Accepted for publication June 1987 